\title{
Wasting and Recovering Time: The Golf Course as Shangri-La
}

Randy Schroeder*

Department of English, Mount Royal University, Canada

*Corresponding author: Randy Schroeder, Associate Professor, Department of English, Mount Royal University, Canada, Tel: 403 440-6265; E-mail: rschroeder@mtroyal.ca

Received date: June 18, 2014; Accepted date: July 29, 2014; Published date: August 6, 2014

Copyright: @2014 Schroeder R, et al. This is an open-access article distributed under the terms of the Creative Commons Attribution License, which permits unrestricted use, distribution, and reproduction in any medium, provided the original author and source are credited.

\section{Short Communication}

I have a friend who critiques my urban lifestyle. He lives in a golfcourse suburb, or, as he puts it, "nature." While his position is easy to mock, more interesting is the puzzle his subjectivity and mine present: what kind of representational apparatus would account for his vision of nature and my mockery of his vision? Do we balance each other on a semiotic teeter-totter? Intrigued, I carried out a "phenomenological" experiment one Sunday afternoon by driving through a Calgary golf exurb named Elbow Valley, a neighborhood in a gorgeous section of foothills, well treed, designed with views and seamed with parklets and pathways. For the first ten minutes I marveled, and thought about complexity and integration; after ten I found everything tedious. I couldn't discount the clichéd sense that I was touring a film set or section of Disneyland. Something felt missing-not absent, but attenuated, like an imbalance between order and turbulence. Surely this landscape, like all others, was haunted by excess. But the repressions felt so strong that I doubted there was any chance of genuine novelty or creative advance ever arising. Of course, my experiment was really anything but phenomenological, since I could not remotely bracket the local; indeed, the local-from the architecture to my preconceptions-suffused my consciousness. How much did it cost to live in this nature, so carefully bundled around and into this golf course? How did the landscape loan its meanings to the course, and the course, in turn, to the exurb, in a cycle both centrifugal and centripetal?

A day earlier at Starbucks, I encountered a full page ad for Panacea Financial in the Globe and Mail, which exhorted "In the event of a bad investment, continue playing golf [1]". Again, the golf course presented me with an entanglement. Is golf the guarantee of portfolio recovery? Or is it opposite of finance, and its therapeutic counterpoint? If the latter, why is golf so expensive? Why are those least likely to play also those least likely to invest? I was reminded of three curious items from my research into Bhutanese democracy. First, a document from Standford's conservative Hoover Institution that proposed the phenomenon of "counterfeit" democracy, in which nonwesternized nations eager to align with capitalist democracy apparently ensure that their officials and leaders are seen to play golf. The pretenders listed include Saudi princes, Japanese businessmen, Argentine Colonels and Russian Politicians [2]. Second, an article in Banff's Crag and Canyon that winkingly listed the advantages of Rocky Mountain golf, which ostensibly exceeds and escapes the boundaries of suburban golf in a numinous context of wilderness and possibility [3]. The article implicitly judges the commercialization of lowland courses, where golfers are not obliged to walk, and will never see genuine nature in the form of forested valleys or fordable rivers. Third, a 2003 article in Golf Digest that lauded Bhutan's Royal Thimphu golf course, then the world's most remote [4]. Again, the enticements are the elevation and the lack of commercialization, implicitly linked. As with every article on Bhutanese golf I've read-including those by
Bhutanese writers cleverly trading on Orientalist fantasies-this one cites and celebrates the country's isolated Buddhist traditions, its unique emergent democracy and its Gross National Happiness Index, three topics rarely seen in leisure journalism, and three not easily reconciled.

What to make of this cluster of meanings? Golf is somehow nature; it simultaneously fosters and resists democracy, capitalism, commercialization, exurbia, and alienation. The cluster hints that urban, suburban, exurban and other lowland golf courses embody not only respite, but contamination and loss. The GNH might be seen here as a utopian figure imbedded in the otherwise mundane blandishments of leisure journalism. In real life, the GNH attempts to reconcile four pillars: environmental preservation, cultural promotion, economic development and good governance. But if we note the inevitable sparks between environmentalism, tourism and commerce, and view the four pillars as a semiotic rectangle, the GNH might then represent a circle squared, or, to cite Walt Whitman, a deific square chanted. This poetic reference is more than fancy, for in "Chanting the Square Deific" Whitman presents a spiritual-dare I say quasiBuddhist?-resolution of oppositions, especially the ancient and the modern, and offers conciliations that have usually felt like broken promises. He offers an impossible gift, better than paradise: balance regained.

I had an acquaintance who was a golf course superintendent. He got cancer at thirty, and blamed the pesticides. Whether he was right or not, golf courses are often noted as bonsai ecological disasters. Pesticides, herbicides, fungicides and fertilizers are reportedly linked not only to a variety of human diseases, but to nutrient loading and leaching, pollution of groundwater, concentrated arsenic in lakes, nitrites in moving water, poisoning of adjacent watersheds, soil contamination, even air toxicity. The construction and maintenance of courses are also frequently linked with ecological displacement and disruption: alterations in habitat, loss of established grasslands, denudation, erosion, toxic impacts on aquatic organisms, and establishment of pernicious monocultures-the list is well-known and extensive.

There are at least two material responses to the problem, which represent the limiting cases on a spectrum. The first we might call "green gadgeteering," of the celebratory version typified by a Buckminster Fuller or Ray Kurzweil, and sometimes described more modestly as "technological solutions and economic diversification." This position is typified by ongoing proposals for course management: using remnant vegetation to "provide offsets for biodiversity" [5]; using filters to clean water before it reaches local waterways (US Agricultural Research Service) [6]; managing amphibian populations and introducing new species of toad and frog [7]; maintaining healthier turf sward by controlling earthworm activity [8]; turf reduction [9]; restoration of biodiversity through "ecologically simplified landscapes" [10]; routine water testing the list is potentially 
and necessarily endless [11]. The second response presents as more extreme, and involves some version of banishing golf courses altogether. This position is typified by the global Antigolf movement [12], which launched in 1993, claims deep worldwide involvement, and on its website links golf not only with ecological disaster, but with destruction of local economies, displacement of local communities, continuity of globalized exploitation, violation of human rights, and maintenance of elitist ideologies and toxic narratives of leisure. The web is littered with spooky sites rallying or recounting anti-golf activism, manifesting everywhere from India to Indonesia; the midnineties "golf war" in Tepoztlan, Mexico is well documented. (I should briefly mention that there are many possibilities between these extreme responses, like permaculture and other minimally interventionist or nonlinear systems of ecological design, which may or may not work for golf ecology.)

Each position demands an implicit and distinct ontological posture. The gadgeteer works from within a thin ontological slice, in order to accommodate demonstrable solutions, however temporary. His work is enabled by its own blind spots: to consider full interdependence would be to call an eternal meeting of engineers. The anti-golfer works from within an ontological ecology-not unlike those recently proposed by some feminist epistemologists, and long offered by process-relational philosophers-but seems to offer little beyond abolition. The interconnective register inevitably tends towards the poetic and prophetic, or, in neoliberal language, the silly and incomprehensible. As Whitman says in Democratic Vistas, the "huge earth," to those with the right frames of reference, is "lit with the infinite...manifold and oceanic" (465). But what do those with the Cosmic Vision do with one poisoned golf course in one corner of one suburb?

Each material response, then, generates its own practical troubles. The anti-golfer intuitively understands that, unlike a cigar, golf is never just golf. But is it, then, everything? This limit problem is not trivial. As the west's finest process thinker, Alfred North Whitehead, pointed out with respect to his influence and contemporary, Francis Bradley, too much relation with too little process results in a static monism where decision, event, potential, history and even position soften and begin to lose their actuality and acuity (43). The arrow of time is forgotten. In such a world, what is a solution? Even in the realm of what Whitehead calls Presentational Immediacy (61)-the necessary and ordinary mode of sense perception that appears clear and practical-it is hard to imagine the strident anti-golfer generating more than deferred or utopian options(more on utopia shortly). In a further twist, consider anthropologist Orin Starn's musings that golf, post-Cold-War, has become implicated as the symbol par excellence of the "supposed superiority of American Capitalism and Democracy [13]." He argues that golf's tight connection to globalization and the "excesses of savage capitalism" has worked against its successful export to countries like China. So interdependance, if conceived as process and relation, is seeded with the very novelty that Elbow Falls is missing: unintended consequences.

This is a given, often a delight, for the sophisticated processrelational thinker. It is a delight and a disaster for the gadgeteer, whose ontological slice can never police its own boundaries nor purge its limits from its core. Paradoxically, then, accidents are the primary cost and benefit of gadgeteering, which generates the contradictions of Hurrah Capitalism in almost cartoonish ways as it celebrates its own headaches. Michelle Boon's 2008 study, for example, found that too many overwintering bullfrogs displace reared amphibians introduced to reduce course habitat destruction [14]. Bullfrog tadpoles and predatory fish that frequent human-made ponds must then be reduced to compensate, with new studies necessary to measure the new effects. A small example-but we see the production of solutions that perpetually evolve into new problems, the very conditions necessary for the maintenance of gadgeteering as an economy and persistent mode of commoditization. More predictably, a 2007 study suggests that UK course managers intent on increasing biodiversity are usually in deep conflict with club members [15]. One hardly needs to guess who wins that argument. Curiously, then, the naïve gadgeteer and the naïve relation thinker are confronted with inversions of the same dilemma: once you admit that turbulence cannot be modeled within any symbol system, you have told the truth, but lost your model. Your golf party now includes Derrida, Whitman, feminist epistemologists and other "impractical" thinkers [16,17].

Now imagine golfing a wonderfully designed course. It feels like nature: the trees and waterways are appointed perfectly. Yet you might sense, intermittently, at low volume, that something is not quite right with the earthworms below. The disjunctions generated by the material responses have reorganized at a subtler horizon, that of lived experience. To seize these unconscious pulses of affect would require successive interpretive operations that suss out the contradictions from the inside: one is now in the realm of ideology, swept up with all the problems that preside over the history of that definition. As I have suggested, superior golf courses evoke ecological splendor: Rocky Mountain courses, especially, are on offer as landscapes of transcendence and morphic resonance, despite the literal death and disconnection they often embody. So how to resolve these contradictions between registers of lived experience? Following the still visible footprints of two Old School theorists, Raymond Williams and Fredric Jameson (especially Jameson's lifetime project spanning the seminal Political Unconcious and more recent Archaeologies of the Future), I suggest that both collective and individual responses to the disjunctions involve splitting real from imaginary, one of the top ten false distinctions in the neoliberal order. This split allows us to indulge what Jameson calls utopian fancies-private or collective daydreams that symbolically resolve lived contradictions. These fancies can be literal daydreams, or manifest as persistent cultural narratives and images. All are necessarily ephemeral. Golf, like other daydreams, is prone not only to projection, but to progressive displacement: when tensions between the realia and representations of suburban golf can no longer be managed, the fancy migrates upward, into what Simon Schama would call the "unearthly topography" of the Rockies. But what happens when ecological reality impinges on that fancy, too?

Philosopher and magician David Abram, in his infamous Spell of the Sensuous, describes the tensive relationship between spaces of excess-like mountains and horizons-and spaces of the underground [18]. While the roof of the world opens to horizons of infinite promise, the hidden underground paradoxically supports that promise through its very sedimentation and weight (214). Whitehead would have loved this dynamic, since it entails that the past is both objective and immutable, yet somehow also a verb, flowing forward in vectors of process that constrain and enable the actuality of events. Following Abram's vision, I speculate that golf daydreams and advertising schemes now express most richly in the imaginary space of the Himalayas, precisely because such daydreams no longer thrive in our own charted mountain landscapes. As any golf course is a charged mixture of Above and Below, these utopian fancies are grounded in the deeply felt but unacknowledged experience of dissatisfaction, and 
Page 3 of 3

projected further into high and remote territories that are, as advertised, beyond the wastelands: the constrained grids of suburb and domestic park, the pulsing claustrophobia of the Starbuck's and the weekend barbecue, and, somehow, even outside the protocols, spaces and temporalities of globalized democratic capitalism, where landscapes of leisure are both nature and catastrophe, freedom and subjugation, promise and lie. The Bhutanese golf course, in this daydream, reconciles ancient forest with modern grass, "Eastern" interdependence with western reification, spiritual restraint with secular consumption. It becomes a miniature Shangri-la where fairway, green, rough and sandtrap are chanted deifically: here individual freedom, genuine collectivity, rapacious expenditure and healthy landscape are not antagonists, but counterparts in a magical landscape of regained balance, where waste and recovery are in a perpetual dance.

Lately I have been wrestling with some high theory on freedom, decision and economics-in other words, theories of balance. These theories include Laclau and Mouffe's suggestion that the extreme irregularities and displacements in late capitalism are the very conditions of possibility for radical democracy [19]; Zizek's assertion that democracy is divided against itself as a final fetish that protects against its own genuinely terroristic core [20]; and Derrida's late provocation, before his death, that what is most valuable in democracy is not its potential but its infinite deferral, what Peter Gratton calls the "radical perhaps" [21]. Derrida hated last words, so I won't give him any, but instead offer them to Whitman, who loved them, and believed utterly in potential, and was both master dialectician and vivacious nature poet: democracy must "displace all that exists, or that has been produced in the past, under opposite influences". Why? Because the "highest freedom" reconciles individual self-determination with all "relations to other individuals". Now, all relations is a tall order, and we might wonder if this process-relational dialectic is just empty proto-New Ageism. Whitman's answer is typically in the prophetic register: "Democracy's history "remains unwritten, because that history has yet to be enacted".

Actually, then, why not enact Whitman's future, and pollute his optimism? Why not give the last word to Tiger Woods, who in his infamous adultery confession chanted an eleven-sided deific, and tried to square past, future, fame, fortune, dissatisfaction, authenticity, dislocation, loss, representation, alienation, and-tellingly-Bhuddist spirituality? Woods expressed the impossible wish of the neoliberalized subject, briefly interrupted into awareness of context and ecosystem. He demonstrated Adorno's prickly observation that "one must have tradition in oneself, in order to hate it properly" [22]. He said: "I need to regain my balance" [23].

\section{References}

1. Panacea Financial (2010) Advertisement. Globe and Mail

2. Jowitt K (2010) Communism Democracy and Golf. Hoover Digest: Research and Opinion on Public Policy 1.

3. Whyte J (1992) When Peaks and People Meet. Mountain Chronicles: A Collection of Columns on the Canadian Rockies from the Banff Crag and Canyon 1975-1991.

4. Barton J (2010) The World's Most Remote Golf Course: The Tiny Kingdom of Bhutan Wedged Between India and China Struggles with a New World-and a New Game. Golf Digest. SPORTDiscus: 130-132.

5. Burgin S, Wotherspoon D (2009) The Potential for Golf Courses to Support Restoration of Biodiversity for BioBanking Offsets. Urban Ecosystems $12: 145-155$.

6. US Agricultural Research Service (2009) New Filter Could Clean Golf Course Runoff. Water Environment and Technology 28.

7. Boone MD, Semlitsch RD, Mosby C (2008) Suitability of Golf Course Ponds for Amphibian Metamorphosis When Bullfrogs are Removed. Conservation Biology 172-179.

8. Bartlett M, James I, Harris J, Ritz K (2008) Earthworm Community Structure on Five English Golf Courses. Applied Soil Ecology 39: 336-341.

9. Singer R, Richardson F (2009) 8 Tips for Improving municipal Golf Courses. Parks and Recreation 44: 22-27.

10. Colding J, Carl F (2009) The Role of Golf Courses in Biodiversity Conservation and Ecosystem Management. Ecosystems 12: 191-206.

11. Weintraub B (2009) The Greening of Golf Courses. Parks and Recreation 44: 26-32.

12. Global Anti-golf Movement (2010) Manifesto.

13. Whitehead AN (1978) Process and Reality. An Essay in Cosmology.

14. Starn O (2006) Golf and Globalization. Golf Politics.

15. Hammond R, Hudson D (2007) Environmental Management of UK Golf Courses for Biodiversity-Attitudes and Actions. Landscape and Urban Planning 83: 127-136.

16. Derrida J (2005) Rogues: Two Essays On Reason trans. Pascale-Anne Brault and Michael Naas.

17. Whitman W (1959) Complete Poetry and Selected Prose.

18. Abram D (1996) The Spell of the Sensuous. Perception and Language in a More-than-human world.

19. Laclau E, Mouffe C (2001) Hegemony and Socialist Strategy: Towards a Radical Democratic Politics.

20. Zizek S (2010) Living in the End Times.

21. Gratton P (2009) Derrida and the Limits of Sovereign Reason: Freedom Equality but Not Fraternity. Telos 148: 141-159.

22. Adorno T (2006) Minima Moralia: Reflections from Damaged Life.

23. Gibson O (2010) Tiger Woods Begs For Forgiveness For Selfish and Foolish Behavior. Guardian. 